\title{
Two new species of the Rhyacophila nigrocephala species group from China (Insecta, Trichoptera, Rhyacophilidae)
}

\author{
Changhai SUN \\ Department of Entomology, Nanjing Agricultural University, Jiangsu 210095, China. \\ Email: chsun@njau.edu.cn \\ urn:1sid:zoobank.org:author:DD6E8DE5-3E20-4F9E-BC80-5FF92CE798F1
}

\begin{abstract}
Two new species of the Rhyacophila nigrocephala species group, $R$. voluta sp. nov. and $R$. linguiformis sp. nov., are described, diagnosed and illustrated. Rhyacophila voluta sp. nov. is similar to $R$. pentagona Malicky \& Sun, 2002 in male genitalia, but can be diagnosed by the inferior appendages of the same length as the complex of preanal appendages and dorsal lobe of segment IX, fused base of the basal segments of inferior appendages, and slightly incised distal margin of apical segment of inferior appendage. Rhyacophila linguiformis sp. nov. is similar to R. rima Sun \& Yang, 1995 and R. esorima Mey, 1996 in male genitalia, but can be diagnosed by the progressively narrowed complex of preanal appendages and the dorsal lobe of segment X, the short anal sclerites, and the small gap between the upper and lower lobes of apical segment of inferior appendages. An updated checklist of 23 species recorded from China is presented.
\end{abstract}

Key words. Caddisfly, taxonomy, species group, subgroup.

Sun C. 2017. Two new species of the Rhyacophila nigrocephala species group from China (Insecta, Trichoptera, Rhyacophilidae). European Journal of Taxonomy 300: 1-10. https://doi.org/10.5852/ejt.2017.300

\section{Introduction}

The Rhyacophila nigrocephala diagnostic species group was established by Ross (1956) to contain 14 species known at that time. Schmid (1970) placed it in his Rhyacophila divaricata Branch, and increased the number of species in the group to 32, with one subspecies (R. putata temba Schmid, 1970 from Manipur, India). Afterwards, several authors reported 29 species from China (Sun \& Yang 1995, 1999; Malicky 1995; Malicky \& Sun 2002), Vietnam (Oláh 1987; Mey 1996; Armitage \& Arefina-Armitage 2003), Nepal (Kiss 2011), Thailand (Malicky 1991; Malicky \& Chantaramongkol 1993; Malicky et al. 2004), Japan (Kobayashi 1987) and Korea (Botosaneanu 1970; Kobayashi 1989). Furthermore, additional distribution data have been appended to some species (Armitage et al. 2005; Chuluunbat \& Morse 2007; Hsu \& Chen 2003; Ito 1999; Ivanov 2011; Kiss 2013; Malicky 2007, 2012, 2014; Mey 2005; Morse 2016; Nozaki \& Nakamura 2007; Nuntakwang et al. 2007; Ohkawa \& Hattori 2007; Potikha 2005; Satake \& Kuranishi 2007; Wityi et al. 2015; Yang et al. 2005).

Currently, 61 species / subspecies are placed into the R. nigrocephala species group, 53 species / subspecies from the Oriental Biogeographic Region, 7 from the Palearctic Biogeographic Region, and 3 occur in 
both the Oriental and Palearctic Biogeographic Region. In addition, 9 species belong to $R$. manuleata sub-group, 52 species/subspecies fall into the $R$. nigrocephala sub-group.

Of 23 Chinese species of the Rhyacophila nigrocephala species group (Table 1), 19 are from Oriental China, 1 from Palearctic China and 4 occur in both Oriental and Palearctic China. Furthermore, 5 species belong to the $R$. manuleata sub-group and 18 belong to the $R$. nigrocephala sub-group.

The purpose of this article is to describe two new species, Rhyacophila linguiformis sp. nov. and $R$. voluta sp. nov., both from Guangdong, Oriental China. As a result, the total number of species of the $R$. nigrocephala species group now known from China is 25 , and the total number of species/subspecies in the species group is 63 .

\section{Material and methods}

The specimens examined were collected using pan traps with $15-\mathrm{w}$ ultraviolet light tubes set near streams. Rhyacophilid adults were then sorted and stored in $100 \%$ alcohol.

The genitalia preparation procedure follows that used by Xu et al. (2014). The structures of the male genitalia were traced in pencil using a drawing tube on a Nikon Eclipse $80 i$ microscope. Original pencil drawings were inked digitally with Photoshop ${ }^{\circledR}$ CS4 version to produce illustrations. Each male abdomen was transferred to a microvial with $80 \%$ ethanol and stored together with the remainder of the specimen in a larger jar.

Terminology for male genitalia follows that of Schmid (1970). Type specimens have been deposited in the Insect Collection, Nanjing Agricultural University, Nanjing, Jiangsu Province, PR China.

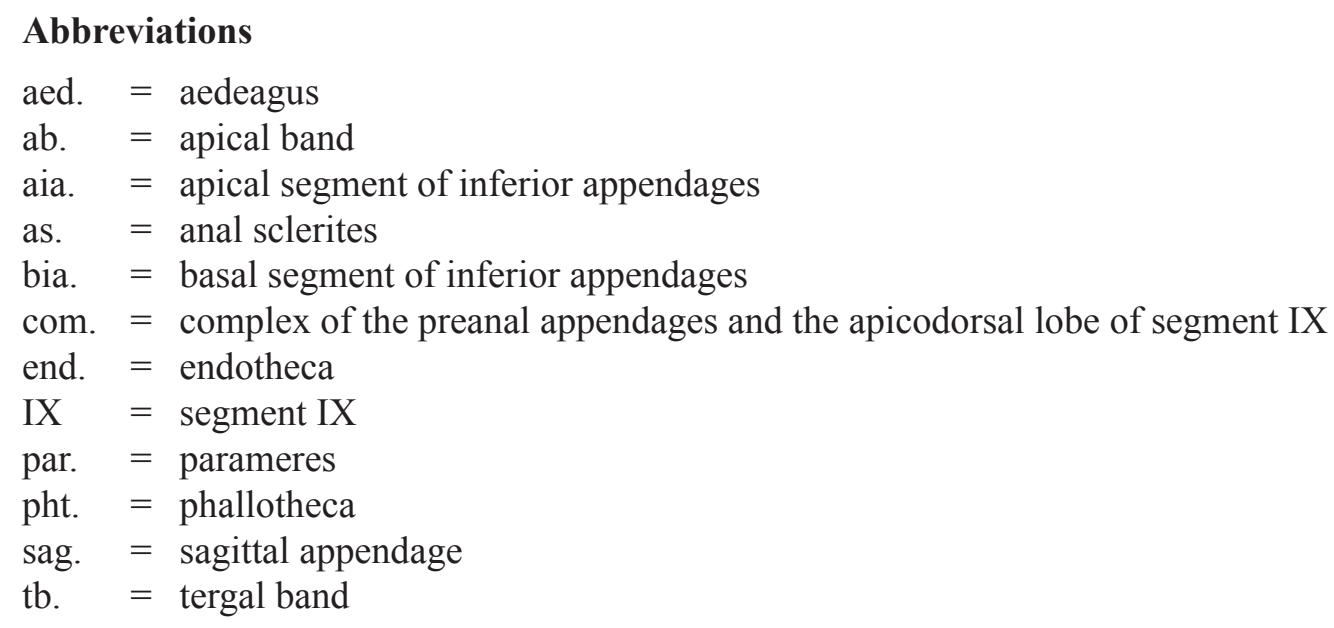

\section{Institutional acronyms:}

NJAU $=$ Nanjing Agricultural University, Nanjing, China 
Table 1. Species of the Rhyacophila nigrocephala species-group recorded from China.

\begin{tabular}{ll}
\hline Sub-groups and species & Distribution \\
\hline altoincisiva Hwang, 1957 & R. manuleata sub-group \\
manuleata Martynov, 1934 & China (Fujian) \\
melli Ulmer, 1926 & China (Taiwan), Japan, Korea, Oussouri, USSR (Far East) \\
shikotsuensis Iwata, 1927 & China (Guangdong) \\
linguiformis sp. nov. & China (Taiwan), Japan, Russia \\
rima Sun \& Yang, 1995 & China (Guangdong) \\
\hline & China (Jiangxi) \\
\hline formosana Ulmer, 1927 & R. nigrocephala sub-group \\
kimminsi Ross, 1956 & China (Taiwan) \\
lata Martynov, 1918 & China (Taiwan) \\
& China (Heilongjiang), Mongolia, Oussouri, Russia (southern Far \\
nigrocephala Iwata, 1927 & East, Siberia) \\
tecta Morton, 1900 & China (Taiwan), Japan \\
amblyodonta Sun \& Yang, 1999 & Bhutan, China (Taiwan), India (Khasi Hills, Kameng), Myanmar \\
anakdjeram Malicky, 1995 & China (Sichuan, Yunnan) \\
anaksungai Malicky, 1995 & China (Sichuan) \\
celata Sun \& Yang, 1999 & China (Sichuan) \\
cuneata Sun \& Yang, 1999 & China (Guizhou) \\
euryphylla Sun \& Yang, 1999 & China (Zhejiang) \\
exilis Sun \& Yang, 1999 & China (Sichuan) \\
forcipata Malicky \& Sun, 2002 & China (Sichuan, Yunnan) \\
hadestril Malicky \& Sun, 2002 & China (Shaanxi) \\
hamosa Sun, 1995 & China (Zhejiang) \\
pentagona Malicky \& Sun, 2002 & China (Zhejiang) \\
unisegmentalis Malicky \& Sun, 2002 & China (Yunnan) \\
vascula Malicky \& Sun, 2002 & China (Shaanxi) \\
voluta sp. nov. & China (Guangdong) \\
\hline
\end{tabular}

\section{Results}

Family Rhyacophilidae Stephens, 1836

Genus Rhyacophila Pictet, 1834

\section{Rhyacophila nigrocephala species group}

Diagnosis (modified from Schmid 1970)

The species group can be diagnosed by the combination of following characters. In the male, segment IX is usually long, with the apicodorsal lobe fused with the preanal appendages into a complex, covering the other portion of the male genitalia. The anal sclerites are fused, with the apex slightly incised mesally and curved upwards, its root is large and curved upwards. The tergal band is slender, flattened dorsoventrally, with the apex sagittal, and has been termed as the sagittal appendage by Ross (1956). 
The apical band is with two lateral arms articulating, with anal sclerites above and with the tergal band beneath. The phallic apparatus is elongate and cylindrical; the aedeagus with the apex is thin; the parameres, if present, are slender. Schmid (1970) recognized two sub-groups, the $R$. manuleata subgroup and the $R$. nigrocephala sub-group.

\section{Rhyacophila manuleata sub-group}

\section{Diagnosis}

Rhyacophila manuleata sub-group is characterized by (1) each apical segment of the inferior appendages deeply incised, (2) phallus apparatus simple, (3) the parameres present, (4) the base of the basal segment of inferior appendages not fused mesally.

\section{Rhyacophila linguiformis sp. nov. urn:1sid:zoobank.org:act:A2708F26-9F2B-49C3-BCA2-D18F180A2FF9}

Fig. 1

\section{Diagnosis}

This new species is similar to R. rima Sun \& Yang, 1995 from Jiangxi, China and R. esorima Mey, 1996 from Vietnam in the male genitalia, all of them belong to the $R$. manuleata sub-group, but the new species differs in: (1) the complex of preanal appendages and the dorsal lobe of segment $\mathrm{X}$ in dorsal view is progressively narrowed from the base to the apex, but in $R$. rima the complex is somewhat spindleshaped, and in $R$. erorima the complex with two parallel lateral margins, which become narrow near the apex; (2) the anal sclerites in lateral view are shorter than the complex, with the apex moderately concave in dorsal view, but in $R$. rima it extends beyond the apex of the complex, with a deep incision mesally in dorsal view, and in $R$. esorima it extends to the complex, with the apex slightly incised mesally; (3) the gap between the upper and the lower lobes of each inferior appendage is smaller than the width of the lower lobe, but in both $R$. rima and in $R$. esorima the gap at least equals the width of each lower lobe.
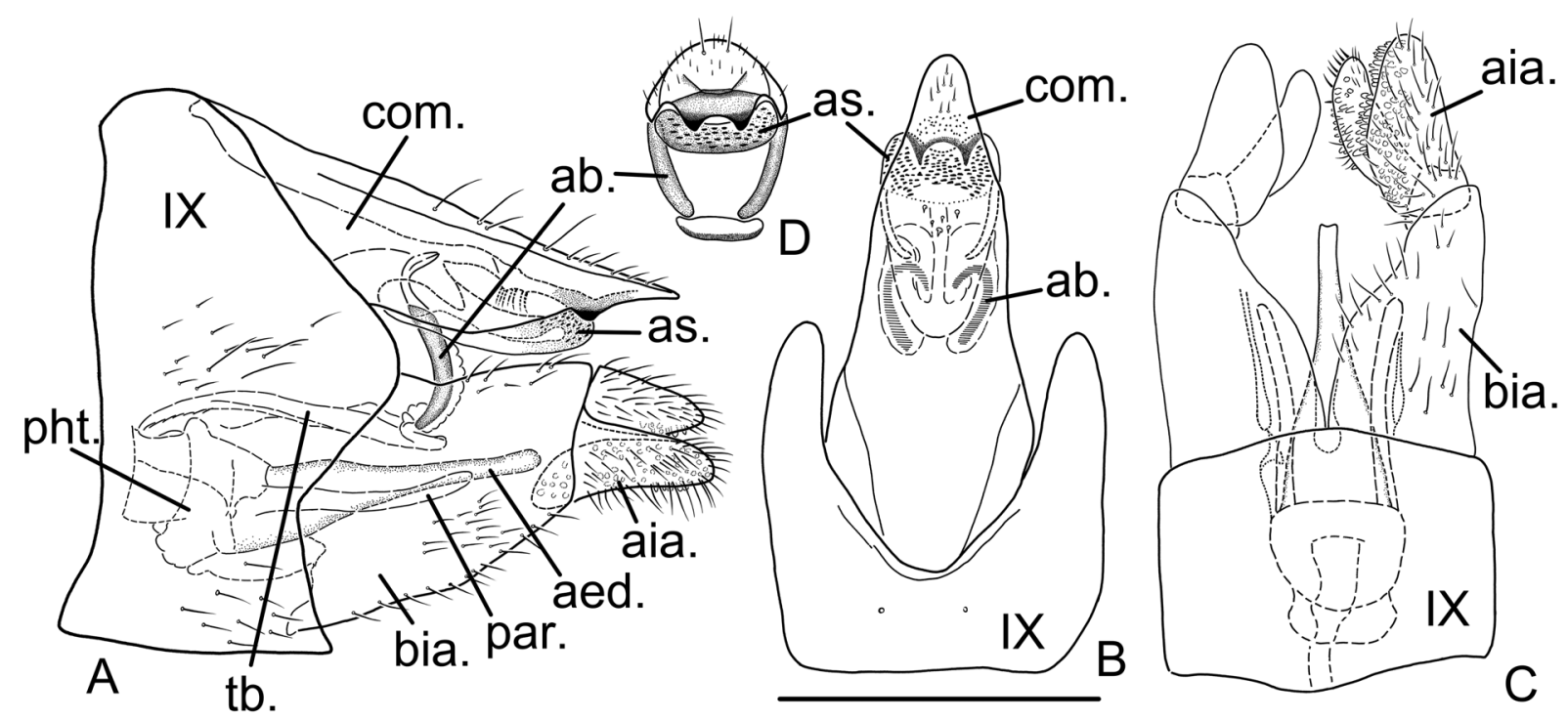

Fig. 1. Rhyacophila linguiformis sp. nov., male genitalia. A. Lateral view. B. Dorsal view. C. Ventral view. D. Complex of preanal appendages and apicodorsal lobe of segment IX, caudal view. Scale bar: $0.5 \mathrm{~mm}$. 


\section{Etymology}

The species epithet comes from the Latin word "linguiformis", meaning "tongue-shaped", in reference to the tongue-shaped complex of the preanal appendages and the apicodorsal lobe of segment IX.

\section{Type material}

\section{Holotype}

CHINA: $\widehat{\lambda}$, in alcohol, collected in Guangdong Province, Xinyi County, town of Dacheng, Dawuling Nature Reserve, stream inside entrance of Reserve, $111.19^{\circ}$ E, $22.27^{\circ}$ N, 1021 m, 26 May 2004, Xin Zhou and Sanbao Tang leg. (NJAU).

\section{Description}

\section{Male}

BoDy. Length of each forewing: $1.0 \mathrm{~mm}(\mathrm{n}=1)$. Body (in alcohol) dark brown. Head dark brown; eyes black; antennae dark brown, palpi brown. Thorax dark brown dorsally, brown laterally and ventrally; legs brown; wings brown. Abdomen dark brown dorsally and brown ventrally.

Male Genitalia (Fig. 1A-D). Segment IX (IX) in lateral view with each anterior margin straight, each posterior margin sinuate, dorsal margins short and ventral margins long (Fig. 1A); in dorsal view anterior margin straight, and posterior margin with deep U-shaped incision (Fig. 1B). Preanal appendages and apicodorsal lobe of segment IX fused tightly into complex (com.), in lateral view complex somewhat trapezoidal with upper margin 3 times as long as the lower margin (Fig. 1A), and in dorsal view somewhat tongue-shaped, tapering from base to apex (Fig. 1B). Anal sclerites (as., Fig. 1A) in lateral view barshaped, about $1 / 2$ times as long as upper margin of complex. Apical band (ab.) in lateral view slender, slightly curved posteriad (Fig. 1A). Tergal band (tb.) membranous, in lateral view elongate. Phallotheca (pht.) irregular in lateral view, somewhat rectangular in ventral view; aedeagus (aed.) with a large base, then progressively narrowed to rounded apex; paired parameres (par.) slender and shorter than aedeagus. Basal segments of inferior appendages (bia.) setose sparsely, each is subrectangular in lateral view and triangular in ventral view; apical segments (aia.) setose densely, each divided into 2 lobes, each upper lobe slightly shorter than lower one.

\section{Female}

Unknown.

\section{Distribution}

China (Guangdong).

\section{Rhyacophila nigrocephala sub-group}

\section{Diagnosis}

The Rhyacophila nigrocephala sub-group can be diagnosed by the combinations of following characters: (1) none of the apical segments of the inferior appendages is incised; (2) parameres absent; (3) basal segments of inferior appendages fused basomesally. 


\section{Rhyacophila voluta sp. nov. \\ urn:1sid:zoobank.org:act:DF10323C-1202-4D75-8CB2-9C2C5B87A026}

Fig. 2

\section{Diagnosis}

The new species belongs to the $R$. nigrocephala sub-group, and is similar to $R$. pentagona Malicky \& Sun, 2002 from Yunnan, China, in the male genitalia, but differs in: (1) the inferior appendages of about the same length as the complex of the preanal appendages and the apicodorsal lobe of segment IX (obviously shorter than the complex in R. pentagona); (2) the basal segments of the inferior appendages in lateral view are somewhat rectangular and in ventral view with their bases fused (pentagonal in R. pentagona, and their bases not fused obviously); (3) the apical segments of the inferior appendages with each distal margin slightly concave (straight in $R$. pentagona).

\section{Etymology}

The species epithet comes from the Latin word "volutus", meaning "having been curled", in reference to the subapical margin of the complex of the preanal appendages and the apicodorsal lobe of segment $\mathrm{X}$ extending upward into a curled lamella.

\section{Type material}

\section{Holotype}

CHINA: $\hat{\delta}$, in alcohol, collected in Guangdong Province, Ruyuan County, Nanling National Nature Preserve, Lao-peng Keng at cascading tributary, Route X327, marker $22.5 \mathrm{~km}, 113.01^{\circ} \mathrm{E}, 24.93^{\circ} \mathrm{N}$, 1110 m, 18-19 May 2004, John C. Morse, Xiaoli Tong and Xin Zhou leg. (NJAU).

\section{Paratypes}

CHINA: $4 \hat{\delta} \hat{\sigma}$, in alcohol, collected at the same locality along with the holotype, except marker $17.45 \mathrm{~km}, 113.03^{\circ} \mathrm{E}, 24.91^{\circ} \mathrm{N}, 935 \mathrm{~m}, 21-22$ May 2004, John C. Morse and Changhai Sun (NJAU).

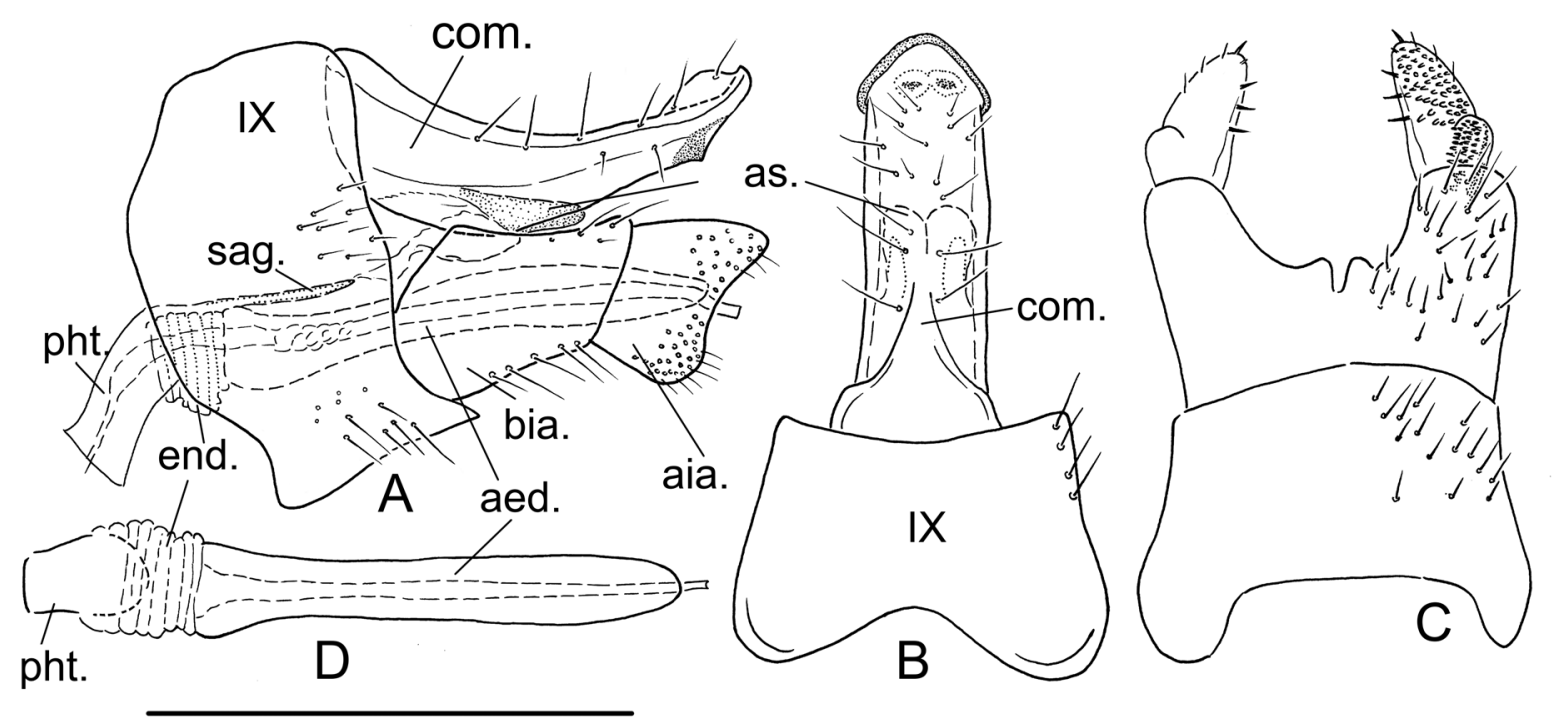

Fig. 2. Rhyacophila voluta sp. nov., male genitalia. A. Lateral view. B. Dorsal view. C. Segment IX and inferior appendages, ventral view. D. Phallic apparatus, ventral view. Scale bar: $0.5 \mathrm{~mm}$. 


\section{Description}

\section{Male}

Body. Length $5.0 \mathrm{~mm}(\mathrm{n}=3)$, length of each forewing 6.0-7.0 mm $(\mathrm{n}=5)$. Body (in alcohol) brown. Head dark brown; antennae brown; palpi light brown, eyes black. Thorax brown dorsally, yellow laterally and ventrally; wings dark brown; legs with coxae, trochanters and femora yellow, remainder parts dark brown, spurs dark brown. Abdomen dark brown dorsally and yellowish brown ventrally.

Male genitalia (Fig. 2A-C). Segment IX (IX) in lateral view with middle portion of each anterior margin (about half the height of segment IX) straight and slightly projecting anteriad, each posterior margin almost straight, with posteroventral angle slightly projecting posteriad, dorsal and ventral margins straight; in dorsal view, anterior margin incised in V-shaped, posterior margin slightly concave; in ventral view anterior margin with broad shallow incision and posterior margin convex slightly. Apicodorsal lobe of segment IX and preanal appendages fused into complex (com.), in lateral view it curved downward at middle, with broad base and thin apex, subapex with dorsal margin extended upward to form lamella; in dorsal view complex with the two lateral margins parallel to each other, and apex triangular, the lamella curled. Anal sclerites (as.) large, with base fused into complex of apicodorsal lobe and preanal appendages, in lateral view somewhat triangular, in dorsal view its apex incised. Apical band (ab.) membranous. Sagittal appendage (sag.) in lateral view style-like. Basal segment of each inferior appendage (bia.) in lateral view somewhat rectangular, base slightly broader than apex in lateral view, in ventral view bases fused mesally; apical segment of each inferior appendage (aia.) in lateral view trapezoidal, with distal margin shallowly concave, in ventral view somewhat triangular. Phallic apparatus simple: phallotheca (pht.) tubular in lateral view and trapezoidal in ventral view, endotheca (end.) membranous, aedeagus (aed.) tubular, with apex narrowed suddenly.

\section{Female}

Unknown.

\section{Distribution}

China (Guangdong).

\section{Discussion}

The $R$. nigrocephala species group has the highest diversity of species within the genus Rhyacophila, with 63 members up to date. All species are exclusively distributed in both the Eastern Palearctic and Oriental biogeographic regions.

Twenty-five species of $R$. nigrocephala species group (including the 2 new species described in this paper) are recorded from China (Table 1), which is about $40 \%$ of the world fauna of the group. Among them, 18 species are endemic to China, distributed in the provinces of Guangdong ( $3 \mathrm{spp}$.), Fujian (1 sp.), Jiangxi (1 sp.), Guizhou (1 sp.), Shaanxi (3 spp.), Sichuan (3 spp.), Yunnan (1 sp.), both Sichuan and Yunnan (2 spp.), Taiwan (2 spp.), and Zhejiang (3 spp.); $R$. lata Martynov, 1918 is the only Palearctic species, distributed in Heilongjiang, China, Mongolia and Russia; R. manuleata Martynov, 1934, R. nigrocephala Iwata, 1927 and R. shikotsuensis Iwata, 1927 are widespread in Palearctic Japan, Korea and even Russia to Oriental Taiwan, but are not recognized from mainland China, this situation may be due to poor sampling efforts in mainland China. In recent papers, $R$. nigrocephala was recorded from the Liao River basin in the northeast of China (Zhao et al. 2015), and R. manuleata was reported from Mt. Dabie, Hubei Province (Qiu \& Yan 2016). So far, R. tecta Morton, 1900 is recognized from the Oriental Region, being widely distributed in Bhutan, China (Taiwan), India (Khasi Hills, Kameng) and Myanmar. In summary, the distribution of members of the $R$. nigrocephala species group is confined to 
the Eastern Palearctic and Oriental biogeographic regions, but more samples are bound to reveal a more extended distribution of each species within the group.

\section{Acknowledgements}

I am grateful to Dr. John C. Morse of the Clemson University, USA, for his long term help and support in the study on Trichoptera. Thanks are also due to the team members of the collecting trip to the provinces of Guang-dong and Guang-xi in 2004 and to the province of Jiang-xi in 2005, co-organized by Dr. Morse and Prof. Yang Lian-fang of the Nanjing Agricultural University, PR China, who are acknowledged for their cooperation and help. I am also grateful to the two anonymous reviewers and the editors for their valuable comments that improved the quality of the manuscript. This research was supported by Fundamental Research Funds for the Central University (KYZ201106), the National Natural Science Foundation of China (NSFC, No. 412715125), and the United States National Science Foundation (DEB-0316504).

\section{References}

Armitage B.J. \& Arefina T.I. 2003. The genus Rhyacophila Pictet (Trichoptera: Rhyacophilidae) in Vietman. Aquatic Insects 25: 95-124. https://doi.org/10.1076/aqin.25.2.95.14037

Armitage B.J., Mey W., Arefina T.I. \& Schefter P.W. 2005. The caddisfly fauna (Insecta: Trichoptera) of Vietnam. In: Tanida K. \& Rossiter A. (eds) Proceedings of the 11th International Symposium on Trichoptera: 25-37. Tokai University Press, Hadano.

Botosaneanu L. 1970. Trichoptères de la République Démocratique-Populaire de la Corée. Annales Zoologici 27: 275-359.

Chuluunbat S. \& Morse J.C. 2007. Caddisflies (Insecta: Trichoptera) of Selenge River Basin, Mongolia. In: Bueno-Soria J., Barba-Álvarez R. \& Armitage B.J. (eds) Proceedings of the XII ${ }^{\text {th }}$ International Symposium on Trichoptera: 51-57. The Caddis Press, Columbus, Ohio.

Hsu L.-P. \& Chen C.-S. 2003. A new species and a new record of Rhyacophilid caddisflies from Taiwan (Trichoptera: Rhyacophilidae). Formosan Entomologist 23: 151-156.

Ito T. 1999. Life histories of three free-living caddisflies in a headwater stream of Hokkaido, northern Japan. Biology of Inland Waters 14: 28-34.

Ivanov V.D. 2011. Caddisflies of Russia: Fauna and biodiversity. Zoosymposia: 171-209.

Kiss O. 2011. Two new species of Rhyacophila (Trichoptera, Rhyacophilidae) from Nepal. Acta Zoologica Academiae Scientiorum Hungarica 57 (2): 111-116.

Kiss O. 2013. Three new species of Rhyacophila (Trichoptera: Rhyacophilidae) from Taiwan and Nepal. Zootaxa 3640: 213-223. https://doi.org/10.11646/zootaxa.3640.2.5

Kobayashi M. 1987. Systematic study of the caddisflies from Taiwan, with descriptions of eleven new species (Trichoptera: Insecta). Bulletin of the Kanagawa Prefectural Museum 17: 37-48.

Kobayashi M. 1989. A taxonomic study on the Trichoptera of South Korea, with description of four new species (Insecta). Bulletin of the Kanagawa Prefectural Museum 18: 1-9.

Malicky H. 1991. Some unusual caddisflies (Trichoptera) from southeastern Asia (Studies on caddisflies of Thailand, No. 5). In: Tomaszewski C. (ed.) Proceedings of the 6th International Symposium on Trichoptera: 381-384. Poznan, Poland, Adam Mickiewicz University Press.

Malicky H. 1995. Weitere neue Köcherfliegen (Trichoptera) aus Asien (Arbeit Nr. 18 über thailändische Köcherfliegen). Braueria 22: 11-26. 
Malicky H. 2007. Köcherfliegen aus Bhutan (Insecta, Trichoptera). Linzer biologische Beiträge 39: 475-517.

Malicky H. 2012. Neue asiatische Köcherfliegen aus neuen Ausbeuten (Insecta, Trichoptera). Linzer biologische Beiträge 44: 1263-1310.

Malicky H. 2014. Köcherfliegen (Trichoptera) von Taiwan, mit Neubeschreibungen. Linzer biologische Beiträge 46: 1607-1646.

Malicky H. \& Chantaramongkol P. 1993. Neue Trichopteren aus Thailand. Teil 2: Rhyacophilidae, Philopotamidae, Polycentropodidae, Ecnomidae, Psychomyiidae, Xiphocentronidae, Helicopsychidae, Odontoceridae (Arbeiten über thailändische Köcherfliegen Nr. 12) (Fortsetzung). Linzer biologische Beiträge 25 (2): 1137-1187.

Malicky H. \& Sun C. 2002. 25 new species of Rhyacophilidae (Trichoptera) from China. Linzer biologische Beiträge 34: 541-561.

Malicky H., Chantaramongkol P., Bunlue P., Changthong N., Nawvong J., Nuntakwang A., Prommi T., Thamsenanupap P. \& Thapanya D. 2004. 27 neue Köcherfliegen aus Thailand (Insecta, Trichoptera) (36. Arbeit über thailändische Köcherfliegen). Linzer biologische Beiträge 36: 287-304.

Mey W. 1996. Die Köcherfliegenfauna des Fan Si Pan-Massivs in Nord-Vietnam 1. Beschreibung neuer und endemischer Arten aus den Unterordnungen Spicipalpia und Annulipalpia (Trichoptera). Beiträge zur Entomologie 46: 39-65.

Mey W. 2005. The Fan Si Pan Massif in North Vietnam - towards a reference locality for Trichoptera in SE Asia. In: Tanida K. \& Rossiter A. (eds) Proceedings of the 11th International Symposium on Trichoptera: 273-284.Tokai University Press, Hadano.

Morse J.C. (ed.) 2016. Trichoptera World Checklist. Available from http://entweb.clemson.edu/database/ trichopt/index.htm [accessed 27 Apr. 2016]

Nozaki T. \& Nakamura S. 2007. Caddisflies (Trichoptera) collected from Hiroshima Prefecture, western Honshu, Japan (II). Miscellaneous Reports of the Hiwa Museum of Natural History 48: 91-101.

Nuntakwang A., Chantaramongkol P. \& Courtney G.W. 2007. Biodiversity and biogeographic connections of Trichoptera from mountain streams of northern Thailand. In: Bueno-Soria J., BarbaÁlvarez R. \& Armitage B.J. (eds) Proceedings of the XII International Symposium on Trichoptera: 257-262, The Caddis Press, Columbus, Ohio.

Ohkawa A. \& Hattori T. 2007. The caddisflies (Trichoptera) of the University Forest in Hokkaido, the University of Tokyo. I. Rhyacophilidae. In: Bueno-Soria J., Barba-Álvarez R. \& Armitage B.J. (eds) Proceedings of the XII In International Symposium on Trichoptera: 263-274. The Caddis Press, Columbus, Ohio.

Oláh J. 1987. Seven new Rhyacophila species from Vietnam (Trichoptera: Rhyacophilidae). Folia Entomologica Hungarica Rovartani közlemények 48: 141-150.

Potikha Y.V. 2005. Structural characteristics of the Trichoptera in two watercourses of the central Sikhote-Alin in 1977 and 1996. In: Tanida K. \& Rossiter A. (eds) Proceedings of the 11th International Symposium on Trichoptera: 347-353. Tokai University Press, Kanagawa.

Qiu S. \& Yan Y. 2016. New species and new records of genus Rhyacophila Pictet (Trichoptera: Rhyacophilidae) from Dabie Mountains, east-central China. Zootaxa 4171 (2): 347-356. https://doi. org/10.11646/zootaxa.4171.2.7

Ross H.H. 1956. Evolution and Classification of Mountain Caddisflies. University of Illinois Press, Urbana, Illinois. 
Satake K. \& Kuranishi R.B. 2007. Further studies on caddisflies (Insecta: Trichoptera) collected from the Bonin Islands and Izu Archipelago, Japan. In: Bueno-Soria J., Barba-Álvarez R. \& Armitage B.J. (eds) Proceedings of the XII International Symposium on Trichoptera: 279-284, The Caddis Press, Columbus, Ohio.

Schmid F. 1970. Le genre Rhyacophila et la Famille des Rhyacophilidae (Trichoptera). Mémoires de la Société Entomologique du Canada 66, Entomological Society of Canada, Ottawa.

Sun C. \& Yang L. 1995. Studies on the genus Rhyacophila (Trichoptera) in China (1). Braueria 22: $27-32$.

Sun C. \& Yang L. 1999. Descriptions of five new species of the genus Rhyacophila (Trichoptera: Rhyacophilidae) from China. Entomotaxonomia 21: 39-46.

Wityi H., Nozaki T. \& Fujino T. 2015. A List of Myanmar Caddisflies (Trichoptera) including Recently Collected Data. Entomological Research Bulletin 31: 41-55.

Xu J.-H., Wang B.-X. \& Sun C.-H. 2014. The Stenopsyche simplex Species Group from China with descriptions of three new species (Trichoptera: Stenopsychidae). Zootaxa 3785: 217-230. https://doi. org/10.11646/zootaxa.3785.2.5

Yang L.F., Sun C.H., Wang B.X. \& Morse J.C. 2005. Present status of Chinese Trichoptera, with an annotated checklist. In: Tanida K. \& Rossiter A. (eds) Proceedings of the 11th International Symposium on Trichoptera: 441-460. Tokai University Press, Hadano-shi, Kanagawa, Japan.

Zhao R., Gao X., Ding S., Zhang Y., Qu X. \& Liu S. 2015. Tolerance values of macroinvertebrate taxa in Liao River basin. Acta Ecologica Sinica 35 (14): 4797-4809. https://doi.org/10.5846/stxb201311082699

Manuscript received: 27 April 2016

Manuscript accepted: 22 July 2016

Published on: 15 March 2017

Topic editor: Gavin Broad

Desk editor: Kristiaan Hoedemakers

Printed versions of all papers are also deposited in the libraries of the institutes that are members of the EJT consortium: Muséum national d'Histoire naturelle, Paris, France; Botanic Garden Meise, Belgium; Royal Museum for Central Africa, Tervuren, Belgium; Natural History Museum, London, United Kingdom; Royal Belgian Institute of Natural Sciences, Brussels, Belgium; Natural History Museum of Denmark, Copenhagen, Denmark; Naturalis Biodiversity Center, Leiden, the Netherlands. 